\title{
The Relationship between Person-organization fit and Organizational Cynicism in Higher Education Industry
}

\author{
Payman Molaie ${ }^{1}$, Okeke Emma Obum ${ }^{2}$, Rahayu Tasnim ${ }^{3}$, Jameel Khan ${ }^{4}$ \\ ${ }^{1,2}$ Azman Hashim International Business school, Universiti Teknologi Malaysia \\ ${ }^{3}$ Malaysia-Japan International institute of Technology, Universiti Teknologi Malaysia \\ ${ }^{4}$ Department of Business Education, University of Punjab
}

\begin{abstract}
Organizational cynicism has been an area of concern for the management of higher education. The purpose of this study is to examine whether the academic perception of person-organization fit has a significant impact on organizational cynicism. Data for the research was collected through a selfadministered survey and was analyzed using partial least square structural equation modelling. The findings of the study revealed that the person-organization fit has a significant and negative influence on the cynicism. These findings showed that management reduces negative attitudes among academics by adopting strategies that not only fulfil employees' needs and preferences but also conform to their values and goals. The limitations and directions for future research are also discussed.
\end{abstract}

\section{Key words: Organizational cynicism; person-organization fit; higher education; and PLS-SEM}

\section{INTRODUCTION}

It has been found that person-organization fit influences on employees' satisfaction, commitment, and turnover intention [1]. However, scant focus has been paid to explore the link of P-O fit with cynicism. Extant literature on person-organization fit can be categorized into two strands. The first strands of the research argue that fit between person and organization enhances employees' performance [2], satisfaction [3], productivity [4], organization citizenship behavior, and intention to stay. Moreover, P-O fit has been found to enhance employees' perception of fit with job and vocation [3], [5], [6]. Another stream of research suggests that personorganization misfit is detrimental to both employees and the organization. For employees, P-O misfit is found to encourage turnover intention, job dissatisfaction [7], and withdrawal behavior [8]. For an organization, P-O fit misfit reduces employees' citizenship behavior and commitment to the organization [9], [10]. Research has also shown that when an individual do not feel fit with the organization, they are less likely to put extra effort [11]. This lack of commitment and poor citizenship behaviour, in turn, adversely affects the organization's productivity and performance [4], [12].

In this study, the researcher focuses on the P-O fit. P$\mathrm{O}$ fit is an elusive concept and refers to the fit between organization and person [13]. In other words, $\mathrm{P}-\mathrm{O}$ fit is conceptualized as the compatibility of employee's values and goals with those of the organization [14]. In the literature, scholars have used either values or goals congruence to measure $\mathrm{P}-\mathrm{O}$ fit [9], [15]. Other studies have used both values and goals for the measurement of P-O fit [3], [16]. Hence, following the literature, this study measure P-O fit with goals and values.

Although the significance of P-O fit is widely acknowledged in the literature [9], [10], [15], [17], [18], only a few scholarships have studied the influence of P-O fit on cynicism. Cynicism is defined as "a negative attitude toward one's employing organization in general, and toward its procedures, processes, and management, that is based on a conviction that these elements generally work against the employee's best interests" (Wilkerson, 2002, p. 533). It is a negative work outcome that is predicted by a lack of trust among co-workers, transformational leadership, and job-related stress [20]. Though, to some extent, scholars have explored the predictors of cynicism [20]-[22]. However, studies on the association between cynicism and P-O fit are limited. In this article, we explore the influence of $\mathrm{P}-\mathrm{O}$ fit on cynicism.

In doing so, this research improves the body of knowledge by elucidating the negative influence of the P-O fit on turnover intention. This study also makes a practical contribution by specifying that employees' congruence with organization values and goals is essential to reduce their negative attitude toward the organization. 


\section{LITERATURE REVIEW AND HYPOTHESES DEVELOPMENT \\ Person-Organization Fit and Cynicism}

$\mathrm{P}-\mathrm{O}$ fit is defined as the match or the compatibility between person and organization [23], [24]. In other words, P-O fit occurs when employees' and organization's values and goals values are consistent. Research has shown that when employees' values and goals are congruent with the organization, they exhibit a wide range of positive work attitude. For instance, $\mathrm{P}-\mathrm{O}$ fit is found to be linked to job satisfaction, organization commitment, organization citizenship behaviour [3], [10], [15]. In contrast, P-O fit misfit results in negative work outcomes, such as emotional exhaustion and turnover intention [7]. Despite the importance of P-O fit, research on the association between cynicism and $\mathrm{P}-\mathrm{O}$ fit is rare. This study adds to the body of knowledge by exploring the relationship between cynicism and $\mathrm{P}-\mathrm{O}$ fit.

Cynicism is a negative work attitude that reflects an individual feelings toward organization, job, manager, supervisor, and colleague. In fact, it reflects an individual feeling that the employing organization is devoid of honesty and integrity [25]. Research has shown that cynicism is a multidimensional construct. The two dimensions of the cynicism are (1) individual own mistakes, and (2) the individual feeling that the organization with which he or she works is not going to develop [21]. Employees' own mistakes and perceptions about organization development are presumed to engender a negative attitude among employees toward organizations. Previous scholars have also maintained that cynicism is caused by stress, lack of leadership, and lack of trust among co-workers [20], [26], [27], and insufficient social support [22].

Although scholars have explored the predictors of cynism, however, little is know about how to reduce cynism among employees. In this study, we presume that employees' perception of P-O fit is one of the main factors that reduce employees' negative attitudes toward the organization. We believe that when employees perceive that their values and goals are compatible with the values and goals of the organization, then they are less likely to portray a negative attitude. Prior research also shows that $\mathrm{P}-\mathrm{O}$ fit encourages positive attitudes among employees. For instance, [3], [28], [29] found that P-O fit to enhance employees' job satisfaction and organization commitment. P-O fit has also been found to reduce negative attitudes among employees, such as stress, burnout, and turnover intention[4], [15], [30]. However, the influence of $\mathrm{P}-\mathrm{O}$ fit on organizational is rarely investigated. In this study, we predict that when employees believe that their values and goals are identical to the organization, they then are less likely to portray a negative attitude toward organization. Hence, we propose that:
H1: P-O fit negatively associated with organizational cynicism.

\section{METHODOLOGY \\ Sample and context of the study}

Since this study aims to examine the influence of P$\mathrm{O}$ fit on organizational cynism of the employees working in educational institutions, therefore, the target population of this study was the academic staffs of a public sector university in Pakistan. Data from the participants was collected using convenience, a non-probability sampling technique. In total 153 questionnaires were distributed among the academic staffs. Out of 153, 107 questionnaires were returned, representing a $69 \%$ response rate. Out of the 107 questionnaires, 10 cases were discarded based on suspicious responses and missing values. The elimination of 10 cases resulted in the final data of 97 cases.

Of the 97 participants, 39\% $(\mathrm{n}=37)$ were female, and $61 \%(\mathrm{n}=60)$ were male. Regarding their job roles, about $77 \%(\mathrm{n}=75)$ identified as lecturers, $10 \%(\mathrm{n}=$ 10) as assistant professors, and $5 \%(\mathrm{n}=5)$ as associate professors, and 7\% ( $\mathrm{n}=7)$ as professors.

\section{Instruments}

The instruments of the study were measured on a five-point Likert scale. The scale ranged from 1 ("Strongly Disagree") to 5 ("Strongly Agree"). P-O fit was measured by 6-items adopted from Vogel and Feldman (2009). An example item is: "The things that I value in life are very similar to the things that my organization values." For the measurement of cynicism Kim, Bateman, Gilbreath, and Andersson (2009), four items were used. The sample item is "When I think about organization, I feel irritation." The items were slightly modified to make it fit the context of the study.

\section{Data analysis \\ Descriptive Analysis}

In Table 1, the descriptive statistics of the constructs are presented. These statistics include mean, standard deviation, and correlations. The findings showed that $\mathrm{P}-\mathrm{O}$ fit had a negative and significant correlation with organizational cynicism.

Table 1. Mean, standard deviation, and correlation

\begin{tabular}{lllll}
\hline Variables & Mean & SD & $\mathbf{1}$ & $\mathbf{2}$ \\
\hline $\begin{array}{l}\text { Person- } \\
\text { organisation fit }\end{array}$ & 3.23 & .92846 & 1 & \\
$\begin{array}{l}\text { Org. Cynicism } \\
\text { Organ }\end{array}$ & 3.16 & 1.08177 & $.67 * *$ & 1 \\
\hline
\end{tabular}

\section{Analysis and Results}

The data analysis was carried out using Partial Least Squares Structural Equation Modelling (PLS-SEM). 
PLS was deemed to be appropriate for the analysis of the model because the objective of the study was to explain variance in endogenous constructs. In the first steps of data analysis, confirmatory factor analysis was carried out to check the measurement model validity and reliability. In the second step, the structural model was assessed for the significance of the path coefficient using bootstrapping procedure.

\section{Reliability and Validity of Measures}

A confirmatory factor analysis was performed to assess the reliability of the measures. According to Hair, Ringle, and Sarstedt (2011) for an item and construct to be reliable, the values of the factor loading, Composite Reliability (CR), and Cronbach's alpha (CA) should exceed a minimum threshold of 0.70 . The results of the study revealed that all items factor loadings, constructs CA and CR scores are higher than 0.70 , thus confirming the reliability of items and constructs. The constructs also ensured convergent validity since the score of AVE was greater than 0.50 [33]. The inter-construct correlations should be less than the square root of AVE To establish the discriminate validity[34]. The findings, presented in Table 2 showed that the square root of AVE of each construct is higher than the interconstructs correlations (off-diagonal numbers in Table 2), thus providing evidence of discriminant validity.

Table 2. Constructs and items reliability and validity

\begin{tabular}{|l|l|l|l|l|}
\hline \multirow{4}{*}{ Cynicism } & Items & FLs & CA & CRs \\
\cline { 2 - 5 } & OC1 & 0.83 & 0.90 & 0.93 \\
\cline { 2 - 5 } & OC2 & 0.89 & & \\
\cline { 2 - 5 } & OC3 & 0.81 & & \\
\cline { 2 - 5 } & OC4 & 0.85 & & \\
\cline { 2 - 5 } $\begin{array}{l}\text { Person- } \\
\text { organization } \\
\text { fit }\end{array}$ & POF1 & 0.83 & 0.90 & 0.92 \\
\cline { 2 - 5 } & POF2 & 0.85 & & \\
\cline { 2 - 5 } & POF3 & 0.88 & & \\
\cline { 2 - 5 } & POF4 & 0.83 & & \\
\cline { 2 - 5 } & POF5 & 0.77 & & \\
& POF6 & 0.77 & & \\
\hline
\end{tabular}

Table 3. Fornell \& Larcker Criteria

\begin{tabular}{lll}
\hline Constructs & P-O fit & Cynicism \\
\hline Cynicism & 0.878 & \\
P-O fit & 0.710 & 0.825 \\
\hline
\end{tabular}

\section{STRUCTURAL MODEL}

The structural model shows the relationship between latent constructs. The measures of the structural model are the coefficient of determination (R2), blindfolding redundancy measure Q2, effect size f2, and the significance of the path coefficients. R2 represents the explanatory power of the estimated model, and its value greater than 0.10 indicates the predictive power of the model [35]. In this study, the model explained $50.4 \%(\mathrm{R} 2=0.504)$ of the variance in cynicism. These results satisfy Falk and Miller (1992) criteria of the coefficient of determination. Further, the model's predictive relevance was examined using the blindfolding procedure. According to Hair et al. (2018), the model's predictive relevance is accepted if Q2 values are greater than zero. In this study, the Q2 for endogenous construct was larger than zero, thus satisfying the predictive relevance of the model. We also calculated the effect size of the model. The study revealed that $\mathrm{P}-\mathrm{O}$ fit had a significant effect on organization cynicism.

Besides, the significance level of the path coefficient was estimated using a bootstrapping procedure using 5,000 subsamples. The results of $\beta=-0.710, \mathrm{t}=$ $12.024, \mathrm{p}<0.05$ indicates that $\mathrm{P}-\mathrm{O}$ fit had a negative and significant influence on cynicism, thus providing support for $\mathrm{H} 1$.

\section{DISCUSSIONS AND CONCLUSIONS}

The purpose of this study was to examine the influence of $\mathrm{P}-\mathrm{O}$ fit on the organizational cynicism of the academics. Relationships between P-O fit and other important work outcomes have been investigated; however, the relationship between P-O fit and cynicism has received little attention. This study extends the relevant literature by examining the influence of P-O fit on cynicism of the academics. The findings revealed that $\mathrm{P}-\mathrm{O}$ fit is negatively and significantly related cynicism of the academics. This finding implies that when academic perceive that their values and goals are congruent with the organization, then they are less likely to develop negative attitude toward organization. This finding is consistent with the [36] arguments that P-O fit develops a positive attitude among such as satisfaction and organization commitment among employees. The finding also concurs the conclusion of [1], [14] that employees perception of fit with the organization reduces their negative attitude of leaving the job.

\section{IMPLICATIONS}

The theoretical and practical implications of this research are that employees' perception of P-O fit plays a vital role in determining their attitude toward organization. The findings indicate that the organization needs to be aware of the values and goals of the employees. As well, the study indicates that understanding employees needs and preferences, and their knowledge, skills, and competencies are essential for an organization to reduce employees' negative attitude toward organization. Besides, the study indicates that organization need to enhance employees' perception of fit with the organization and job. An organization can improve the fit of a 
person with the job and organization through training, remuneration [37], better hiring practices [38], and provision of high involvement practices [39]. These results imply that faculty members will feel compatible with the job resources, job demands, and organizational values and goals if they are provided with training and development opportunities, they are paid competitive pay, and their performance is appraised relatively.

\section{LIMITATION AND DIRECTION FOR FUTURE RESEARCH}

Though this study makes significant contributions to management and fit literature, certain limitations should be considered while interpreting the findings. First, this study is cross-sectional. Therefore, the possibility of common method bias is high, which may limit the generalizability of the findings. Second, the data was collected from academic staff, which may have resulted in common methods bias; therefore, future researchers are encouraged to collect the data from heterogeneous groups and test the model with longitudinal data. Third, this study was conducted in Pakistan. Therefore, some contextual factors such as country economic conditions (e.g., the availability of job opportunities) and organizational culture may act as a moderator of the relationship between fit and intention to stay. Therefore, future researchers are encouraged to extend the model by incorporating job opportunities and organizational culture as moderators.

\section{References}

[1] A. S. Kakar, R. A. Saufi, and N. N. A. Mansor, "Person-organization fit and job opportunities matter in HRM practices-turnover intention relationship: a moderated mediation model," Amaz. Investig., vol. 8, no. 20, pp. 155-165, 2019.

[2] M. R. W. Hamstra, A. E. M. Van Vianen, and J. Koen, "Does employee perceived personorganization fit promote performance? The moderating role of supervisor perceived personorganization fit," Eur. J. Work Organ. Psychol., vol. 00, no. 00, pp. 1-8, 2018.

[3] R. M. Vogel and D. C. Feldman, "Integrating the levels of person-environment fit: The roles of vocational fit and group fit," J. Vocat. Behav., vol. 75, no. 1, pp. 68-81, 2009.

[4] A. Samad and R. A. Saufi, "A Comparative Review of Turnover Models and Recent Trends in Turnover Literature," J. Manag. Mark. Rev., vol. 2, no. 4, pp. 27-35, 2017.

[5] C. Boon and M. Biron, "Temporal issues in person-organization fit, person-job fit and turnover: The role of leader-member exchange," Hum. Relations, vol. 69 , no. 12, pp. 2177-2200, 2016.

[6] K. Y. T. Yu, "Inter-Relationships among
Different Types of Person-Environment Fit and Job Satisfaction," Appl. Psychol., vol. 65, no. 1, pp. 38-65, 2016.

[7] A. R. Wheeler, V. C. Gallagher, R. L. Brouer, and C. J. Sablynski, "When person-organization (mis) fit and (dis) satisfaction lead to turnover: The moderating role of perceived job mobility," J. Manag. Psychol., vol. 22, no. 2, pp. 203-219, 2007.

[8] S. Rurkkhum, "The impact of personorganization fit and leader-member exchange on withdrawal behaviors in Thailand," AsiaPacific J. Bus. Adm., vol. 10, no. 2-3, pp. 114129, 2018.

[9] D. T. A. M. Kooij and C. Boon, "Perceptions of HR practices, person-organization fit, and affective commitment: The moderating role of career stage," Hum. Resour. Manag. J., vol. 28, no. 1, pp. 61-75, 2018.

[10] A. M. Y. L. Kristof-brown, R. D. Zimmerman, and E. C. Johnson, "Consequences of Individuals' Fit At Work : a Meta-Analysis of Person - Job , Person - Organization, Person Group , and Person - Supervisor Fit," Pers. Psychol., vol. 58, no. 2, pp. 281-342, 2005.

[11] S. A. Goodman and D. J. Svyantek, "Personorganization fit and contextual performance: Do shared values matter," J. Vocat. Behav., vol. 55, no. 2, pp. 254-275, 1999.

[12] H. Rangriz and J. Mehrabi, "The relationship between emotional intelligence, organizational commitment and employees' performance in Iran," Int. J. Bus. Manag., vol. 5, no. 8, pp. 50$56,2010$.

[13] A. Kristof-Brown and R. P. Guay, "Personenvironment fit.," in APA handbook of industrial and organizational psychology, Vol 3: Maintaining, expanding, and contracting the organization., American Psychological Association, 2011, pp. 3-50.

[14] A. S. Kakar, R. A. Saufi, N. N. A. Mansor, and H. Singh, "Work-life balance practices and turnover intention: The mediating role of person-organization fit," Int. J. Adv. Appl. Sci., vol. 6, no. 9, pp. 76-84, Sep. 2019.

[15] M. Andela and M. van der Doef, "A Comprehensive Assessment of the PersonEnvironment Fit Dimensions and Their Relationships With Work-Related Outcomes," J. Career Dev., vol. 46, no. 5, pp. 567-582, 2019.

[16] J. Badger Darrow and T. S. Behrend, "Personenvironment fit is a formative construct," $J$. Vocat. Behav., vol. 103, pp. 117-131, 2017.

[17] N. Rani and A. Samuel, "A study on generational differences in work values and person-organization fit and its effect on turnover intention of Generation Y in India," Manag. Res. Rev., vol. 39, no. 12, pp. 1695- 
1719, 2016.

[18] A. S. Kakar, R. A. Saufi, and H. Singh, "Understanding linkage between human resource management practices and intention to leave: a moderated-mediation conceptual model," in Proceedings of the 2018 International Conference on Information Management \& Management Science, 2018, pp. 114-118.

[19] J. M. Wilkerson, "Organizational cynicism and its impact on human resources management," Hum. Resour. Manag. Perspect. Context. Funct. outcomes, pp. 532-546, 2002.

[20] S. Kim, K. Jung, G. Noh, and L. K. Kang, "What makes employees cynical in public organizations? Antecedents of organizational cynicism," Soc. Behav. Personal. an Int. J., vol. 47, no. 6, pp. 1-10, 2019.

[21] P. M. Brandes, "Organizational cynicism: Its nature, antecedents, and consequences.," 1998.

[22] A. Margelytė-Pleskienè and J. Vveinhardt, "The quintessence of organizational commitment and organizational cynicism," Organ. Vadyb. Sist. Tyrim. Manag. Organ. Syst. Res. Kaunas Vytauto Didžiojo Univ. 2018, T. 80, 2018.

[23] J. A. Chatman, "Matching people and organizations: Selection and socialization in public accounting firms.," in Academy of Management proceedings, 1989, vol. 1989, no. 1, pp. 199-203.

[24] B. Schneider, H. W. Goldstiein, and D. B. Smith, "The ASA framework: An update," Pers. Psychol., vol. 48, no. 4, pp. 747-773, 1995.

[25] J. W. Dean Jr, P. Brandes, and R. Dharwadkar, "Organizational cynicism," Acad. Manag. Rev., vol. 23, no. 2, pp. 341-352, 1998.

[26] M. Rahimi, M. T. Hashim, H. Tahsildari, and P. Khodakarami, "The relationship between perception of equity and job satisfaction among employees of Malaysian universities," Int. J. Innov. Bus. Strateg., vol. 2, 2013.

[27] P. Khodakarami and Z. Zakaria, "The Relationship between Innovative Behavior and Sustainable Development," Eur. J. Bus. Manag., vol. 7, no. 23, pp. 160-169, 2015.

[28] S. Shehab, R. E. A. Rahim, and S. Daud, "Knowledge Sharing Behavior of Nursing Supervisors in Online Healthcare Communities," Int. J. Pharm. Res., vol. 11, no. $1,2019$.

[29] S. Shehab, R. E. A. Rahim, and S. Daud, "A review of individual factors on knowledge sharing: Evidence from the empirical literature," Int. J. Eng. Technol., vol. 7, no. 4, pp. 186-194, 2018.

[30] M. H. Jin, B. McDonald, and J. Park, "PersonOrganization Fit and Turnover Intention: Exploring the Mediating Role of Employee
Followership and Job Satisfaction Through Conservation of Resources Theory," Rev. Public Pers. Adm., vol. 38, no. 2, pp. 167-192, 2018.

[31] T.-Y. Kim, T. S. Bateman, B. Gilbreath, and L. M. Andersson, "Top management credibility and employee cynicism: A comprehensive model," Hum. Relations, vol. 62, no. 10, pp. 1435-1458, 2009.

[32] J. F. Hair, C. M. Ringle, and M. Sarstedt, "PLSSEM: Indeed a Silver Bullet," J. Mark. Theory Pract., vol. 19, no. 2, pp. 139-152, 2011.

[33] J. F. Hair, J. J. Risher, M. Sarstedt, and C. M. Ringle, "When to use and how to report the results of PLS-SEM," Eur. Bus. Rev., pp. 0000, 2018.

[34] C. Fornell and D. F. Larcker, "Evaluating Structural Equation Models with Unobservable Variables and Measurement Error," J. Mark. Res., vol. 18, no. 1, p. 39, 1981.

[35] R. F. Falk and N. B. Miller, A primer for soft modeling. University of Akron Press, 1992.

[36] D. Giauque, F. Resenterra, and M. Siggen, "Antecedents of Job Satisfaction, Organizational Commitment and Stress in a Public Hospital: A P-E Fit Perspective," Public Organ. Rev., vol. 14, no. 2, pp. 201-228, 2014.

[37] A. Presbitero, B. Roxas, and D. Chadee, "Looking beyond HRM practices in enhancing employee retention in BPOs: focus on employee-organization value fit," Int. J. Hum. Resour. Manag., no. May 2015, pp. 1-18, 2015.

[38] C. Ellis, S. T. Skidmore, and J. P. Combs, "The hiring process matters: The role of person-job and person-organization fit in teacher satisfaction," Educ. Adm. Q., vol. 53, no. 3, pp. 448-474, 2017.

[39] S. Kilroy, P. c. Flood, J. Bosak, and and D. Chênevert, "Perceptions of High involvement Work Practices, Person-Organization Fit, and Burnout: A Time-Lagged Study Of Health Care Employees," Hum. Resour. Manage., vol. 44, no. 5, pp. 1-5, 2016. 